\title{
Threshold effects of hazard mitigation in coastal human-environmental systems
}

\author{
E. D. Lazarus \\ Environmental Dynamics Laboratory, Earth Surface Processes Research Group, School of Earth \& Ocean \\ Sciences, Cardiff University, Main Building, Park Place, Cardiff CF10 3AT, UK \\ Correspondence to: E. D. Lazarus (lazarusED@cf.ac.uk)
}

Received: 26 September 2013 - Published in Earth Surf. Dynam. Discuss.: 21 October 2013

Revised: 9 January 2014 - Accepted: 13 January 2014 - Published: 24 January 2014

\begin{abstract}
Despite improved scientific insight into physical and social dynamics related to natural disasters, the financial cost of extreme events continues to rise. This paradox is particularly evident along developed coastlines, where future hazards are projected to intensify with consequences of climate change, and where the presence of valuable infrastructure exacerbates risk. By design, coastal hazard mitigation buffers human activities against the variability of natural phenomena such as storms. But hazard mitigation also sets up feedbacks between human and natural dynamics. This paper explores developed coastlines as exemplary coupled human-environmental systems in which hazard mitigation is the key coupling mechanism. Results from a simplified numerical model of an agent-managed seawall illustrate the nonlinear effects that economic and physical thresholds can impart into coastal human-environmental system dynamics. The scale of mitigation action affects the time frame over which human activities and natural hazards interact. By accelerating environmental changes observable in some settings over human timescales of years to decades, climate change may temporarily strengthen the coupling between human and environmental dynamics. However, climate change could ultimately result in weaker coupling at those human timescales as mitigation actions increasingly engage global-scale systems.
\end{abstract}

\section{Introduction}

Beach nourishment, artificial dune construction, and shoreline armoring with rock revetments, bulkheads, and sea walls (Fig. 1) are methods of mitigating coastal hazards in developed coastal zones worldwide. Coastal engineering is an old science, and seawalls are an especially old technology: the Phoenicians used them to protect their ports (Marriner et al., 2006), as did early Chinese dynasties (Qingzhou, 1989). In the UK, coastal defences, including many built during the 19th-century Victorian heyday of English seaside resorts (Tunstall and Penning-Rowsell, 1998), now extend along approximately $44 \%$ of the coastline in England and Wales (DEFRA, 2010; BGS, 2012). In the US, shoreline hardening was a common but localized practice that boomed with the post-war housing market of the 1950s, rapidly transforming much of the mid-Atlantic seaboard (Pilkey and Wright, 1988). However, even with this legacy, developed coastlines illustrate a confounding paradox in the modern science of natural hazards and extreme events: that despite "improved...understanding of the physical processes underlying natural hazards and the complexities of social decision-making before, during, and after disasters, ...troubling questions remain about why more progress has not been made in reducing dollar losses" (Mileti, 1999). The UK, the Netherlands, and Belgium still recall "the Big Flood" event of January, 1953, a North Sea storm surge that devastated the English east coast and caused an estimated equivalent GBP 5 billion in damage there (Summers, 1978; Johnson et al., 2005; Lumbroso and Vinet, 2011). The same storm was so catastrophic to the Netherlands that it prompted the now iconic Delta Plan, a massive national investment in flood-control infrastructure (Gerritsen, 2005). The Big Flood again made recent headlines when the Guardian reported a GBP 1 billion funding gap in UK flood-control 
infrastructure, including coastal defenses, with the UK Environment Agency calling for a year-on-year funding increase of GBP 20 million just to maintain current protection (Guardian, 2012). On the other side of the Atlantic, Hurricane Katrina, in August 2005, and Hurricane Sandy, in October 2012, rank as the two most expensive weather-related disasters on record for the US (NOAA, 2013). How is it that coastal disasters, which human ingenuity has been trying to ward off for millennia, are presently both better understood and more costly than ever before?

As a thought experiment, "Mileti's paradox" sets up three hypotheses. First, that extreme weather events, whether through an increasing mean or increasing variability, are becoming more frequent. There is compelling evidence of rising trends in temperature extremes (Rahmstorf and Coumou, 2011) and perhaps in other weather phenomena (Emanuel, 2005; Lubchenco and Karl, 2012). Second, that vulnerable infrastructure and hazard mitigation around the globe is more expensive, beyond inflation, than ever before, and thus the higher financial cost of disasters is independent of any trend toward greater extremes in natural systems. Recent growth in high-value development is apparent on coastlines worldwide (Cooper and McKenna, 2009). In the US, the per-cubic-yard cost of sand for beach nourishment has risen sevenfold since the 1970s (Seabrook, 2013). And third, that a fundamental consequence of hazard mitigation is to filter out small-scale hazard events at the greater expense of infrequent, large ones (Werner and McNamara, 2007). Assessing the risk of a natural hazard involves accounting for the economic value of infrastructure or activities vulnerable to a hazard event, and the probability that an event of a given magnitude will occur. Infrastructural value changes with markets, demographics, land use, and even hazard protection, thus changing the risk associated with a given hazard (Mileti, 1999; Smith, 2013). More difficult to anticipate is the effect of hazard mitigation on the magnitude frequency distribution of the hazard itself, which can change even with a stationary climate.

This third hypothesis arises from considering human activities an "anthropic force" of landscape change (Hooke, 1994, 2000; Haff, 2003) that in some cases results in coupled human-environmental systems: contexts in which human activities and the natural physical environment are dynamically linked, such that the state and behavior of each becomes a function of the other. Note that the logic of the second hypothesis regarding Mileti's paradox, to be independent of the third, assumes that coastal development growth is unrelated to mitigation interventions. In fact, property values and development pressures tend to increase with investment in engineered protection against natural hazards, especially along coastlines; in the absence of hazard mitigation, property values in vulnerable places would be completely different (Mileti, 1999; Werner and McNamara, 2007; Smith, 2013). Parsing the complex dynamics of coupled human-environmental systems (also called coupled humannatural systems, coupled human-landscape systems, and coupled social-ecological systems) is a grand challenge in the physical and social sciences (Kates et al., 2001; Haff, 2003; Liu et al., 2007a; Ostrom et al., 2007; Murray et al., 2009; NRC, 2002, 2010; Ostrom, 2010). This paper explores Mileti's paradox in the context of shoreline protection, a setting in which coupled-system dynamics can manifest over human timescales of years to decades. Drawing on recent advances in coastal morphodynamics involving interactions between human activities and shoreline processes, I present a numerical model of a seawalled shoreline as a human-environmental system governed by economic and physical thresholds, with implications for the function of threshold structures in managed landscapes more generally.

\section{Recent advances in understanding coastal coupled systems}

\subsection{Beach nourishment}

A body of recent numerical modeling research examines the coupled economic-beach dynamics of developed shorelines, with particular attention to beach nourishment (Slott et al., 2008, 2010; Smith et al., 2009; Slott et al., Lazarus et al., 2011; McNamara et al., 2011; Murray et al., 2013; Ells and Murray, 2012; Jin et al., 2013; McNamara and Keeler, 2013; Williams et al., 2013). The work frames beach nourishment as a cumulative cost-benefit optimization problem (Smith et al., 2009), adopting an environmental economics approach typically applied to a renewable resource like timber (e.g., Hartman, 1976). Trees take a certain amount of time to grow into a mature stand. Consequently, in commercial forestry, there is an optimal interval at which trees may be harvested. Harvest them too soon and the timber is worth less money; wait too long and the cumulative return on that patch of forest diminishes. In a coastal town, the width of the beach is analogous to standing timber: the beach constitutes a resource of natural capital (Smith et al., 2009; Gopalakrishnan et al., 2011). A town experiencing shoreline erosion, which depletes that natural capital, may maintain the value of a wide beach through cyclical beach nourishment. Theoretically, like timber harvesting, that nourishment cycle has an optimal frequency: nourishing too often is unnecessarily expensive; waiting too long to nourish results in a narrow beach that negatively affects the town's economic capital. The dynamics of this optimization problem change when a series of towns share the spatial context of a continuous shoreline, such that the management actions of one town begin to affect the beach widths and corresponding management actions of the others. Model scenarios suggest that uncoordinated beach replenishment among neighboring coastal towns may make shoreline erosion rates and mitigation actions more unpredictable, and the use of sand resources more inequitable, as nonlocal effects become more pronounced or unstable in response to forcing conditions associated with climate change, such as sea-level rise and increased storminess. 


\subsection{Engineered structures and management decisions as thresholds}

Foundational to these beach-nourishment models are two fully coupled, agent-based, dynamic landscape models, one describing the evolution of New Orleans, Louisiana (USA), as a city on a major river delta prone to flooding (Werner and McNamara, 2007), and the other the evolution of Ocean City, Maryland (USA), as a resort town on an eroding barrier island prone to storm-driven overwashing (McNamara and Werner, 2008a, b). Both models demonstrate a boom-andbust cycle of development and disaster that is an emergent consequence of the human-environmental coupling rather than an intrinsic characteristic of either the economic or physical components of the system. Moreover, thresholds in states of landscape stability, and in development and hazardmitigation actions by human agents, play an integral role.

In the New Orleans case, artificial levee construction is economically driven; levee height increases in response to flood events that destroy city infrastructure and private property. When flooding destroys property worth more than the cost of levee reconstruction, the levee gets repaired and the local economic market drives property redevelopment. Meanwhile, incremental channelization of the river drives gradual deltaic inundation, increasing the severity of subsequent flood events (e.g., Criss and Shock, 2001). Similarly, in the Ocean City example, resort development and cyclical beach nourishment driven by tourism economics restricts natural barrier dynamics by inhibiting the ability of island width and height to change with sea-level rise. When erosion mitigation eventually becomes economically untenable and beach nourishment becomes too infrequent to hold the barrier island in place, the vulnerable resort is destroyed by a storm event and developer agents site new construction on a more stable part of the island where projected economic return is higher.

A key implication of the New Orleans scenario is that "the long-time-scale dynamics of the modeled system appears to be characterized by an attractor with emergent dynamics in which small-scale floods are filtered out at the expense of amplifying the impact of large floods to be significant disasters, because protection from small-scale floods facilitates development in areas prone to disaster and increased channelization causes an increase in flood size that results in enhanced damage from the low-frequency flood events" (Werner and McNamara, 2007). This same feedback extends to the barrier-island resort scenario, in which "hazardprotection measures filter out high-frequency responses to storms and sea-level rise, but create long-period boom and bust cycles..." (McNamara and Werner, 2008a). The alternative states that arise in these coupled-system examples may be characterized as "undamaged" and "damaged", with long periods of the former punctuated by sudden episodes of the latter. Dynamical systems discourse defines thresholds in terms of transitions between alternative states (Abraham and
Shaw, 1988; Scheffer, 2009), a definition that ecology-based perspectives of human-environmental systems have tended to adopt (Beisner et al., 2003; Groffman et al., 2006; Liu et al., 2007a, b; Chin et al., 2013). But from a geomorphologybased perspective, engineered hazard-mitigation structures like artificial levees and sand dunes, beach nourishment, and seawalls also function as physical thresholds: imposed barriers that a hazard must erode, crest, or breach before it can interact (through flooding, erosion, sediment transport, deposition) with the otherwise sheltered landscape. The threshold between dynamical states is thus the scale, physical integrity, and indirect effects of the mitigating barrier itself, filtering the impact of high-frequency events but literally breaking down with low-frequency recurrence.

Formal definitions of coupled human-environmental systems emphasize the importance of feedbacks that link human activities and natural processes (Turner et al., 2003; Liu et al., 2007a; Chin et al., 2013), but none addresses feedback reciprocity and strength more specifically than the description by Werner and McNamara (2007), who write that coupling "should be strongest where fluvial, oceanic, or atmospheric processes render significant stretches of humanoccupied land vulnerable to large changes and damage, and where market processes assign value to the land and drive measures to protect it from damage. These processes typically operate over the (human) medium scale of perhaps many years to decades, over which landscapes become vulnerable to change and over which markets drive investment in structures, evaluate profits from those investments, and respond to changes in conditions". This definition categorically distinguishes coupled systems from, for example, extractive resource activities that obviate or ignore preventative measures against damage (e.g., McDaniel and Gowdy, 2000). Furthermore, Werner and McNamara (2007) associate strong human-landscape coupling with environmental hazard and risk, which distinguishes their definition from others derived more from social complexity in common-pool resources (e.g., Ostrom, 2010). Coastal environments offer such accessible examples of coupled dynamics because risk exposure to natural hazard is arguably an inherent characteristic of developed coastlines (e.g., Nordstrom, 2000; Kelley and Brothers, 2009). Seawalls, for example, are a ubiquitous response to coastal hazard and risk associated with shoreline erosion and storm surge. Controversy regarding seawalls as a coastal management practice tends to hinge on whether a seawall exacerbates shoreline erosion (Kraus, 1988; Pilkey and Wright, 1998; Kraus and McDougal, 1996; Dean and Dalrymple, 2002), but more broadly, the role of seawalls may be interpreted in terms of a managed physical threshold within a coastal human-environmental system. 

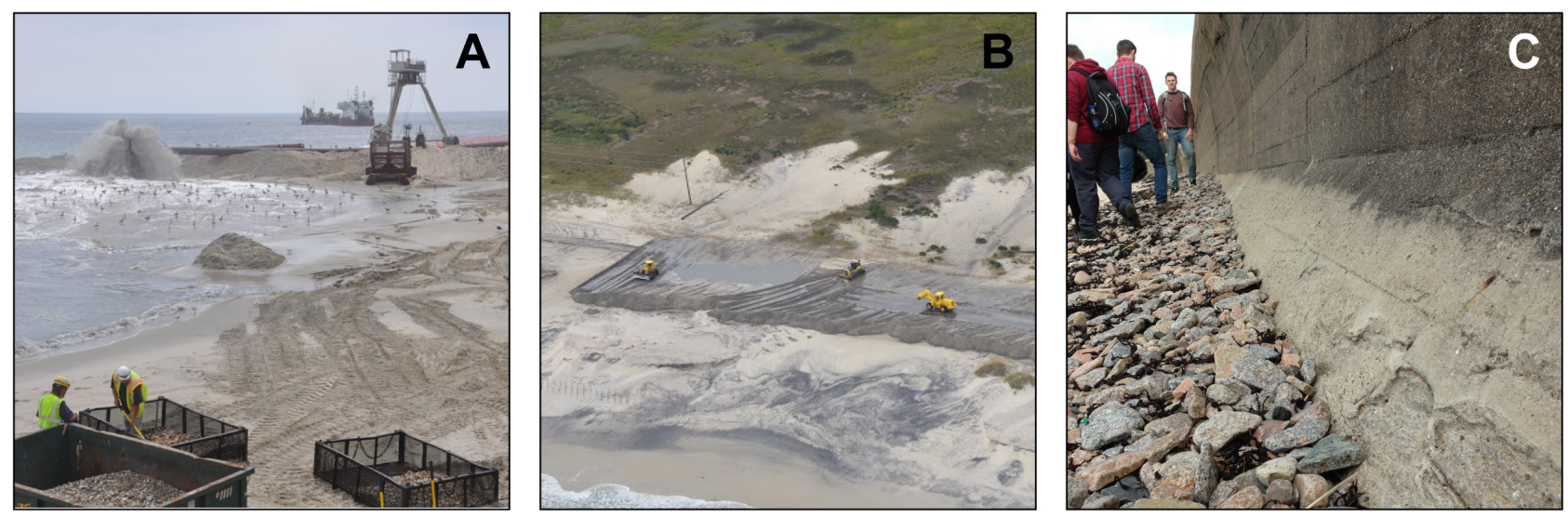

Figure 1. Three examples of typical coastal hazard mitigation practices: (A) beach replenishment in Monmouth, New Jersey (USA), nine months after Hurricane Sandy (photo: A. Coburn, Program for the Study of Developed Shorelines, http://www.psds-wcu.org/); (B) artificial dune reconstruction following an overwash event on Highway 12, North Carolina Outer Banks (USA) (photo: A. Coburn, PSDS); and (C) concrete seawall on the Channel Island of Jersey - note the pitting and fresh scour (light gray band) along the wall base just above the shingle toe.

\section{Example: threshold dynamics in a seawall model}

A deliberately simplified, one-dimensional numerical model demonstrates how a seawalled shoreline may exhibit system dynamics similar to those described for leveed rivers (Criss and Shock, 2001; Werner and McNamara, 2007) and artificial dune fronts on barrier islands (Magliocca et al., 2011). The model combines mechanical interaction between the beach and seawall with decisions by a coastal-manager agent regarding seawall construction and repair. Rather than simulating a particular place, the model represents systemic dynamics of seawalls in abstracted terms.

\subsection{Landscape and damage}

As a motivating analog, the evolution of cliffed coastlines involves a nonlinear relationship between fronting beach width and the rate of cliff erosion (Limber and Murray, 2011). The argument supposes that, comparable to mechanisms for regolith production (Anderson, 2002; Strudley et al., 2006), the beach functions as an erosive tool. The cliff has a natural background retreat rate that a fronting beach then accelerates, at least up to a critical width; beyond that critical width, the beach prevents wave action from reaching the cliff toe, insulating the cliff from erosion.

Here, I assume the seawall acts like a sea cliff (Fig. 2), with a background deterioration rate (in units of $\% \mathrm{yr}^{-1}$ ) that is (1) constant in the absence of a fronting beach; (2) increases with beach width (BW) up to a critical width; and (3) decreases with beach width exceeding the critical width, as a wider beach insulates the seawall from wear. Because the "shoreline" in this one-dimensional model is a single cell, I use a detrended, normalized Brownian time series (generated from the cumulative sum of a white-noise time series) to represent temporally autocorrelated, year-to-year beach width (Fig. 2).

The seawall has two principal variables: wall strength $\left(W_{\mathrm{S}}\right.$, represented as a percentage) and wall height $\left(W_{\mathrm{H}}\right)$. Wall deterioration rate $(\rho)$ goes by the function

$\rho=\left(a \times(\mathrm{BW}+b) \times e^{\left(-c \times W_{\mathrm{s}}\right)}+1\right) / \rho_{\max }$,

where $a, b$, and $c$ are curve-tuning constants (here, $a=40$, $b=0.05$, and $c=-5$; these deliver a corresponding $\rho_{\max }$ of 4.78). Although beach width sets the effective timescale of seawall deterioration, the seawall also experiences one "storm event" per year. Storm magnitude $(S)$ here is analogous to a flood stage or surge height, and is sampled from a normalized, temporally uncorrelated time series of random values. Storm damage the wall sustains in a given year $\left(D_{\text {storm }}\right)$ is calculated as the difference between the scale of the storm $(S)$ and the product of wall height multiplied by wall strength:

$D_{\text {storm }}=S-\left(W_{\mathrm{H}} \times W_{\mathrm{S}}\right)$.

Wall strength is adjusted by both the storm damage and annual deterioration related to beach width:

$W_{\mathrm{S}}^{t+1}=W_{\mathrm{S}}^{t}-\left(\rho+D_{\text {storm }}\right)$,

where $t$ is the model time step (year). If $S$ is less than the product of $W_{\mathrm{H}}$ and $W_{\mathrm{S}}$, then $D_{\text {storm }}=0$.

\subsection{Hazard mitigation}

Hazard mitigation actions affect wall height and wall strength. When the model begins, the initial wall height is set equal to the scale $(S)$ of the first storm. Subsequent increases in wall height and repairs to wall strength are reactionary, lagging storm impacts. As a record of storm-driven 

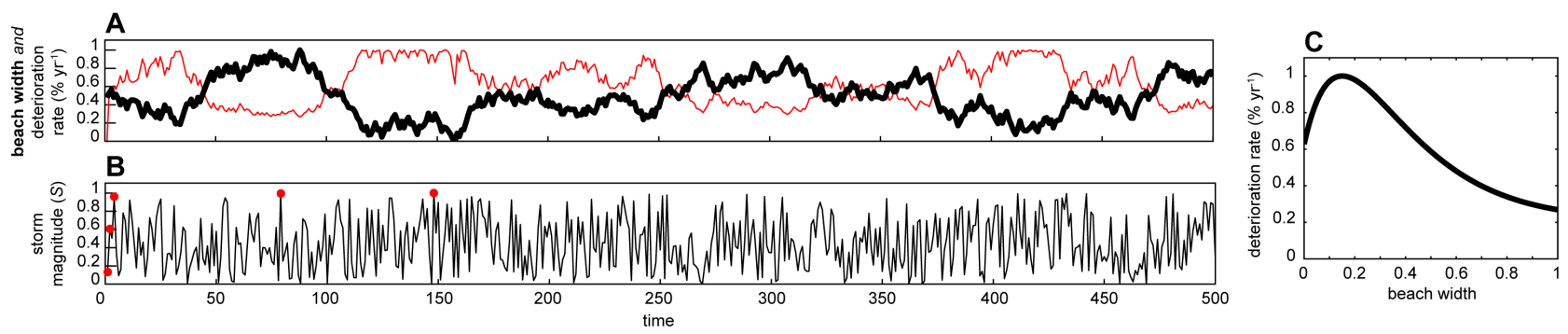

Figure 2. Forcing components for the seawall model. (A) Normalized Brownian signal representing beach width over time (bold) and the corresponding wall deterioration rate (red). (B) Randomized time series of storm events over the simulation period (500 yr); red dots mark record-setting storms. (C) Plot of wall deterioration rate as a function of beach width, motivated by Limber and Murray (2011), Strudley et al. (2006), and Anderson (2002).

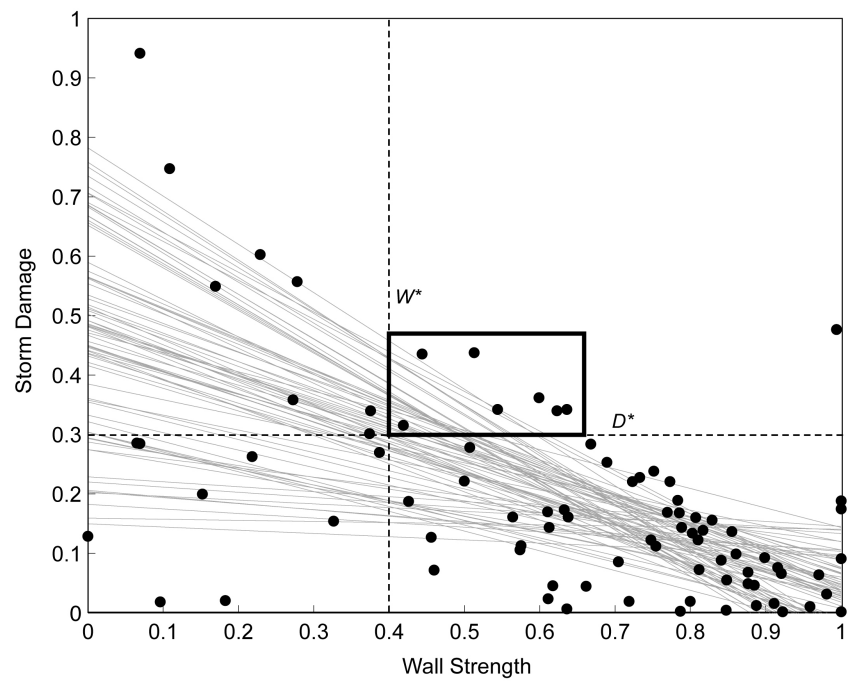

Figure 3. The manager agent uses a line of best fit relating storm damage to wall strength for the previous $N$ damaging storm events to determine whether wall repairs are cost effective, given imposed thresholds for damage tolerance $\left(D^{*}\right)$ and economy of scale $\left(W^{*}\right)$. In this plot $\left(N=10\right.$ events), damage must exceed $D^{*}=0.3$ and at least $40 \%$ of the wall $\left(W^{*}=0.4\right)$ must have deteriorated to warrant repair. Lines of best fit that satisfy these conditions pass through the box shown in bold.

wall damage develops, the coastal-manager agent interprets the record to make decisions about whether or not to repair the wall. When repaired, the wall is always restored to full strength $\left(W_{\mathrm{S}}=100 \%\right)$, and wall height is determined by the largest storm on record $\left(W_{\mathrm{H}}=S^{*}\right)$.

The manager's decision process goes as follows. Each year, the manager looks back over the previous $N$ storms that caused wall damage, plots the damage sustained $\left(D_{\text {storm }}\right)$ against wall strength at the time of the storm for those $N$ events, and calculates a best-fit linear trend through the data points (Fig. 3). The manager requires hindsight of $N>1$ damage events in order to calculate a line, and the bestfit line needs a negative slope to be physically meaningful (e.g., damage is high when wall strength is weak); hindsight of $N>4$ prevents nonsensical (positive) trend calculations. Given a best-fit line, mitigation action then depends on two thresholds: a damage tolerance $\left(D^{*}\right)$, meaning that damage exceeding $D *$ warrants mitigation, and a second threshold requiring that wall strength be degraded beyond a certain percentage $\left(W^{*}\right)$ for repairs to be considered cost effective. In real coastal management settings, fixed costs associated with work crews, equipment, and permitting make capitalworks projects like seawalls subject to economies of scale (e.g., Leafe et al., 1998; Smith et al., 2009). This component of the model reflects the relationship between scale of repair and cost distribution. The manager finds where the calculated best-fit line intersects the ordinate line $D^{*}$. If the abscissa of the intersection is greater than $W^{*}$, then wall repair is deemed cost effective. Indeed, if this condition is satisfied, then repairs to all wall conditions between $W^{*}$ and the abscissa intercept of the best-fit line are cost effective (Fig. 3). This window of cost effectiveness varies each time the manager recalculates the best-fit line. If the abscissa for the bestfit intersection with $D^{*}$ is less than $W^{*}$, the condition for cost effectiveness is not satisfied and the wall is not repaired that year. Both $D^{*}$ and $W^{*}$ are imposed constraints, and remain fixed for the duration of a model run.

\subsection{Results}

Figure 4 shows representative time series of key model parameters: the occurrence of record-setting storms, increases in seawall height, years punctuated by storm-driven damage, and the threshold of cost effectiveness for wall repair calculated by the manager agent. Because the model assumes a stationary climate (zero trend in storm magnitude or sealevel rise), more extreme events occur in the beginning of the time series: the likelihood of an unprecedented extreme (a maximum value in the time series) declines with $1 / t$, where $t$ is the number of previous years in the time series (Rahmstorf and Coumou, 2011). This quick succession of impactful storms drives early investment in wall construction until wall height is nearly equal to the largest possible storm 


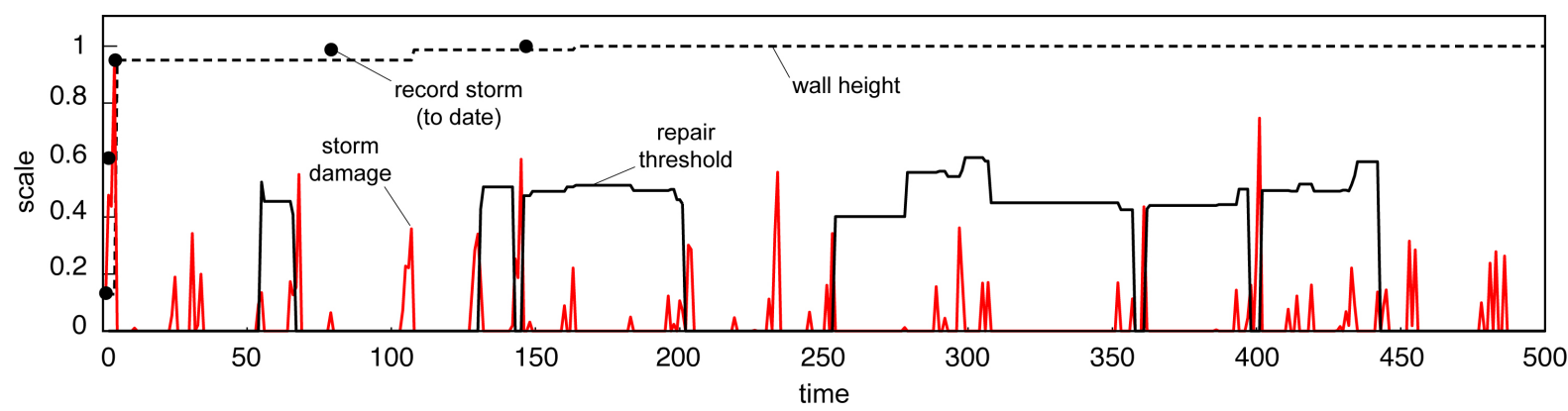

Figure 4. Representative time series of key model parameters (where $D^{*}=0.3, W^{*}=0.4$, and $N=10$ ): record-setting storms (black dots), seawall height (dashed line), storm-driven damage (solid red line), and the threshold of cost effectiveness for wall repair calculated by the manager agent (solid black line).
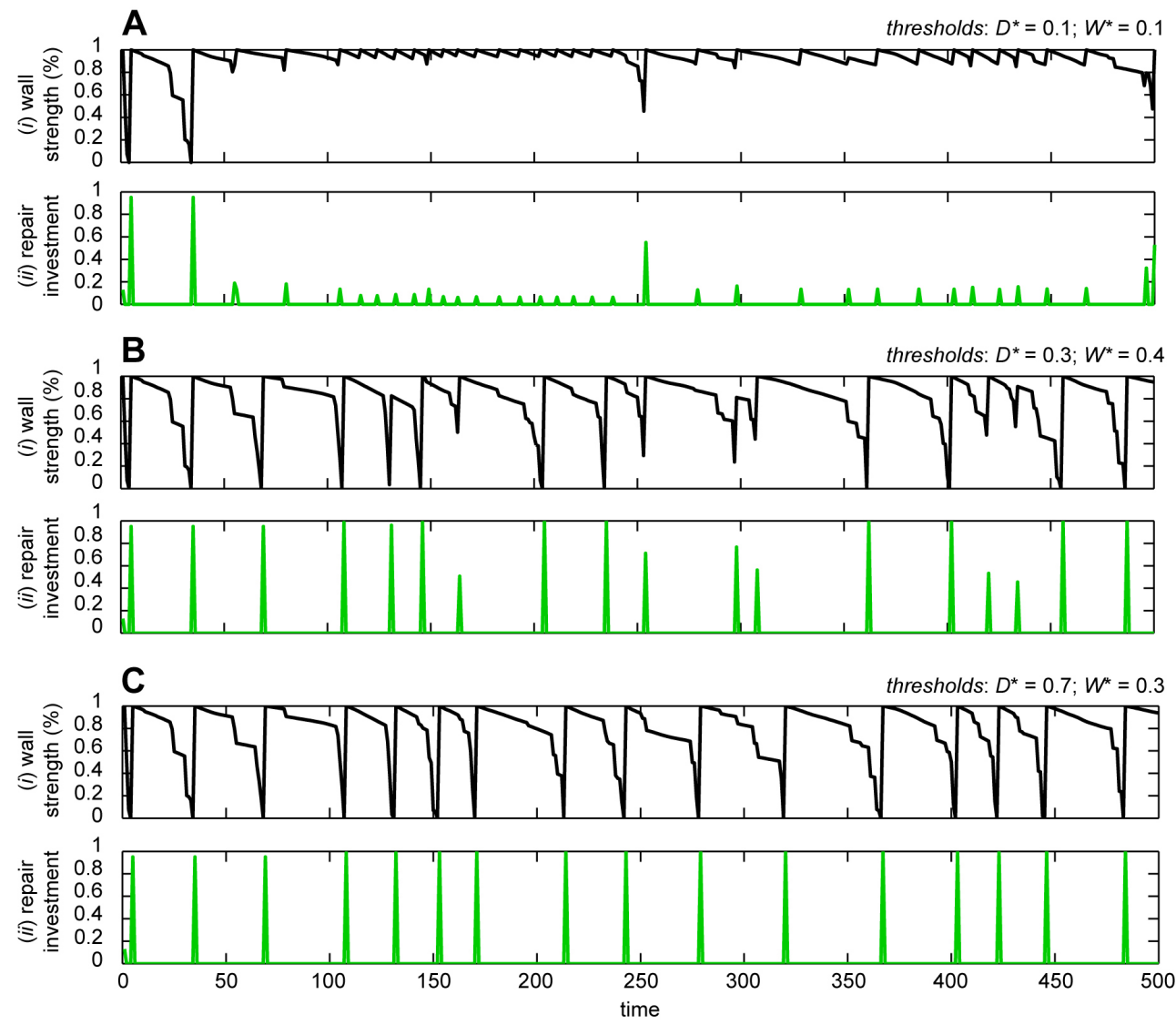

Figure 5. Time series of wall strength and repair investment for three representative pairs of threshold conditions in which: (A) thresholds for damage tolerance and economy of scale are both low $\left(D^{*}=0.1\right.$ and $\left.W^{*}=0.1\right),(\mathbf{B})$ both thresholds are intermediate $\left(D^{*}=0.3\right.$ and $\left.W^{*}=0.4\right)$, and $(\mathbf{C})$ damage tolerance is high and the economy of scale is intermediate $\left(D^{*}=0.7\right.$ and $\left.W^{*}=0.3\right)$. In all three cases shown, $N=10$ events.

event. When the wall is low, storm damage is almost always extensive enough for the manager to opt for wall investment. Annual storm damage decreases as the wall gains height and serves as a more effective barrier against a greater range of storm events.

If the wall did not deteriorate, here the model would effectively stop. Oppositely, if left unrepaired (and in the absence of major storms), the model seawall degrades within a century, a time frame consistent with lifespan estimates for real coastal defenses (e.g., Yokota and Komure, 2003). The model is insensitive to the specific Brownian time series of beach width (Fig. 2); the year-to-year details of the output differ but the model dynamics remain consistent under different forcing patterns. Likewise, adjusting the deterioration rate as a 

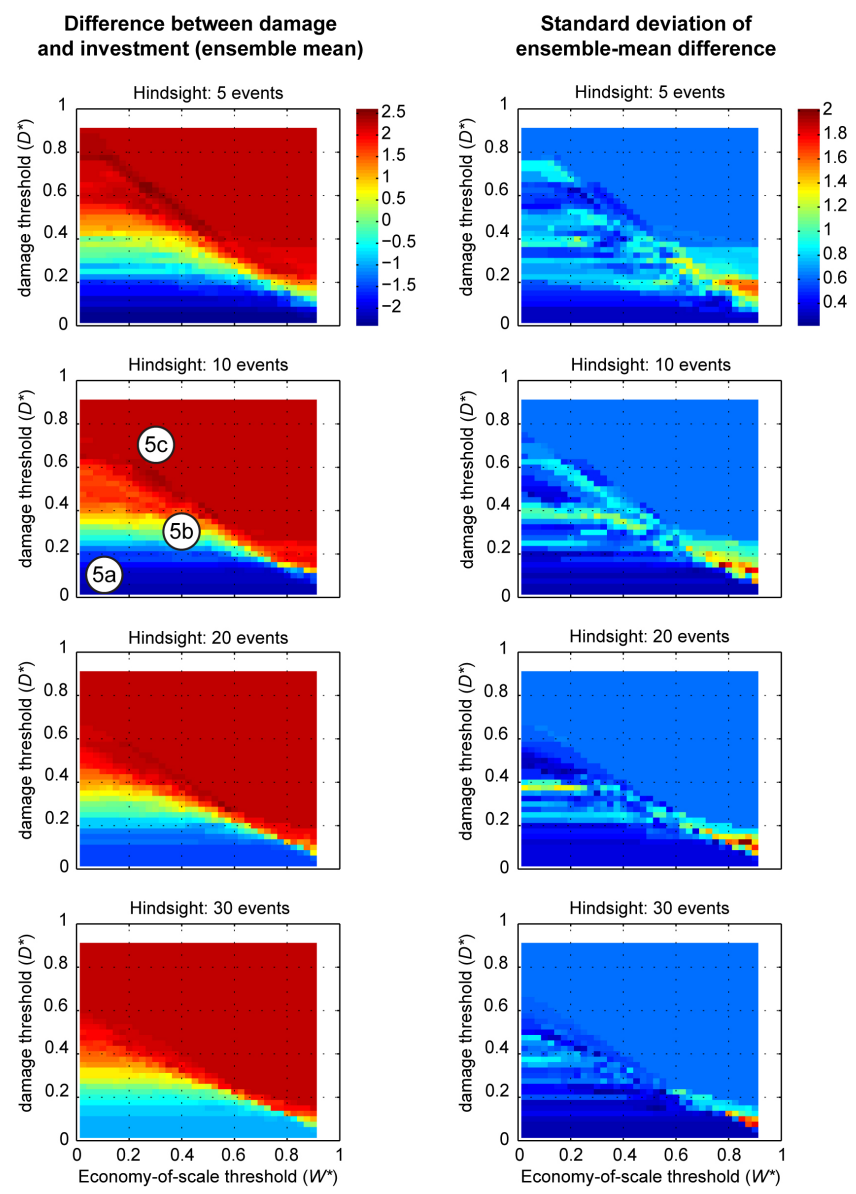

Figure 6. Parameter spaces of threshold pairs $D^{*}$ and $W^{*}$ for four hindsight conditions $(N=5,10,20,30)$. In the left column, color represents the ensemble-mean difference between total storm damage and total investment in repair (derived from 10 different randomized forcing time series for beach width and storms, as in Fig. 2). In the right column, color represents standard deviation around each ensemble mean. Numbered circles indicate parameter pairs shown in Fig. 5.

function of beach width changes the inherent wall lifespan but does not affect the system dynamics. Therefore, maintenance action (including inaction) by the manager agent determines the cumulative record of storm-driven damage. This is emphasized in the temporal record of the manager's economy-of-scale threshold shown in Fig. 4. When the seawall is kept in good repair, data points begin to accumulate in the low-damage, high-wall-strength region of Fig. 3, gradually reducing the slope of the manager's calculated line of best fit. The slope of that line may get so shallow - again, precisely because the wall has been a strong protective barrier - that the manager finds repairs are not cost effective. Once the wall is allowed to degrade, even a storm of average size can result in a costly damage event.

Figure 5 shows indicative time series of the relationship between storm damage and wall investment under three rep- resentative pairs of $D^{*}$ and $W^{*}$ thresholds. When both the damage and economy-of-scale thresholds are low (Fig. 5a), the manager determines that repairing even minor wall deterioration is cost effective: after the seawall is near maximum height, storm damage and associated repair costs remain low through time. When the manager tolerates greater storm damage and requires a greater economy of scale to initiate wall repair, investment in response to damage is erratic (Fig. 5b). Finally, when the manager tolerates extensive storm damage and maintains an economy of scale that requires major wall deterioration to warrant investment in repair, even relatively minor storm damage may necessitate total reconstruction of the seawall (Fig. 5c).

The other imposed parameter governing agent behavior is hindsight $(N)$. Figure 6 shows the parameter space defined by damage tolerance and economy of scale for four different hindsight conditions $(5,10,20$, and $30 \mathrm{yr})$. Each square within each plot in Fig. 6 is the ensemble mean of 10 model trials per parameter pair under different randomized forcing conditions. In the left column, color represents the difference between total storm damage and total wall investment over the duration of a model run; in the right column, color represents standard deviation in the ensemble results. The totals in Fig. 6 illustrate in aggregate what the time series in Fig. 5 show in detail. Minimizing seawall deterioration in the model is an effective but expensive preventative measure against storm damage. Oppositely, infrequent wall repair costs less overall but comes at the expense of large amounts of damage. Moreover, when repairs do happen, they require maximum expenditure. The longer the data series $(N)$ the manager agent uses in the decision calculations, the lower the variability in the system outcome: a best-fit line through 30 data points changes less from year to year than a line through 5 points, tempering the extremes of damage and investment costs over time.

Of course, this model does not simulate the fine-grained intricacy of real shoreline management. The premise assumes sustained managerial commitment to a seawall (e.g., Pilkey and Wright, 1988) and does not explore cost-benefit conditions for abandonment (e.g., McNamara and Keeler, 2013). Strangely enough, the manager's hindsight-based approach to decision making has a surprising, if dubious, recent precedent: in June 2012, the state senate in North Carolina, USA, passed a bill requiring that state agencies use linear extrapolations from historical data to project future sea-level rise, but the state's house of representatives subsequently rejected the measure (Phillips, 2012). Among the model's limitations, a single manager agent treats the seawall as a single managed unit, where a long seawall might be repaired in parts and can extend across adjacent municipalities. Also, the manager agent's decision-making process operates within the imposed bounds of fixed parameters for damage tolerance and economy of scale. But even if those thresholds varied as a function of property value, for example, the results shown still illustrate the kinds of patterns a 
resulting time series would comprise. A trend of increasing property value might drive increased investment in mitigation and thereby decrease total incurred damage (e.g., Fig. 5a). A decline in property value might make hazard mitigation less relevant, and the seawall might be left unrepaired for long periods (e.g., Fig. 5c). The value here of exploring the model's behavior given discrete pairs of bounding conditions is that the underlying mechanisms for system dynamics remain transparent.

Finally, in this construction of the model, wall strength $\left(W_{\mathrm{S}}\right)$ is the only dynamical variable. Changing the height or strength of the seawall does not affect any beach width or storm characteristics: the distribution of the environmental forcing does not change as a result of the hazard mitigation. Lacking a feedback that affects the environmental conditions, the model represents some but not all of the dynamics involved in the third hypothesis for Mileti's paradox. Here the seawall simply acts as a filter, one that can deteriorate (until it protects against only minor events in the environmental forcing signal) and be restored (filtering a wider range of event magnitudes). Moreover, because the deterioration rate $(\rho)$ is a negative exponential function of wall strength, the seawall deteriorates exponentially faster the weaker it is. Punctuated, large damage events thus occur when the manager agent delays wall repairs, but those damage events get no worse with time because there is no feedback on an intermediate timescale (e.g., Werner and McNamara, 2007) to drive an emergent trend in either the coastal development or shoreline components of the system. With the coupling feedback left out, this model serves the expository purpose of illustrating the kind of dynamics that can derive strictly from variability in the forcing conditions imposed on a thresholdgoverned system.

\section{Discussion}

The high financial and economic costs of coastal erosion and flooding are expected to increase further with future sea-level rise and the cumulative effects of anthropogenic changes in coastal sediment fluxes (Mendelsohn and Neumann, 2004; Stern, 2007; Nicholls and Cazenave, 2010; Syvitsky and Kettner, 2011). Some argue that recent coastal development around the world, fueled by the housing market bubble behind the 2008 global financial crisis, has outstripped strategies for sustainable coastal management (Cooper and McKenna, 2009). For a brief period after Hurricane Sandy, US states even debated the prospect of Dutch-scale barrier engineering for parts of the US eastern seaboard (Higgins, 2012; Navarro, 2012). Insight into the dynamics of coastal vulnerability is therefore valuable to government agencies whose remits involve hazard assessment, impact forecasting, and environmental adaptation strategies (Thorne et al., 2007; Plant et al., 2010; MCCIP, 2010; DEFRA 2010). But if protected infrastructure is increasingly valuable or if storm impacts are increasingly powerful, or if both conditions are true, then the cost of damage may go up regardless of how well people understand the hazard. In the presence of a rising trend in either the economic or natural component of the coastal coupled system, is Mileti's paradox inevitable?

Theoretically, situations for which long-term predictions are possible (or reasonable) should lend themselves to optimization, a standard analysis in resource economics that projects into the infinite future to maximize cumulative net benefits (Conrad, 2010; Smith et al., 2009). Ideally, a coastal manager could operate by a cyclical, economically optimal mitigation schedule and never need to deviate from it. For a coupled system in which small changes in environmental conditions might drive large changes in decision making, the more irregularity a manager introduces into a mitigation program, the farther the system's net benefits drift from the optimal outcome (e.g., Lazarus et al., 2011). The seawall model presented here illustrates increased systemic variability in response to frenetic management recalculations (Figs. 5 and 6 ), even under stationary forcing conditions. The time series shown in Fig. 5b, and the regions of the model parameter space where the difference between total damage and total investment hovers around zero in Fig. 6, represent a managed coastal system unwilling to tolerate damage but reluctant to invest in the scale of infrastructural maintenance necessary to prevent it. By contrast, of any managed coastline in the world, the best example of a long-term optimization strategy in practice must be the Netherlands, strategy in practice must be the Netherlands (Kabat et al., 2005, 2009), whose damage-versus-investment trajectory might look more like Fig. 5a. The Dutch Delta Plan has engineered Mileti's paradox into a moot point: the coastal hazard is well understood, the cost of maintenance is high but accepted, and the resulting cost of damage is small.

Although the Delta Plan is a physical threshold of such magnitude that impact from all but the rarest events are preventatively filtered, it is not a solution to sea-level rise. Therefore, the scale of intervention on the Dutch coast has not decoupled human dynamics from natural environmental processes so much as coupled them to the environment at a timescale significantly longer than those most governments treat as dynamically relevant. Such contrasting scales of intervention complicate the suggestion that "climate change, by accelerating the rates of landscape change, tends to strengthen the coupling with human dynamics" (Murray et al., 2013). With various technological innovations throughout history, humans have proven remarkably successful at weakening the strength of coupling between human and environmental dynamics. For example, land clearing in preColumbian Mesoamerica triggered intensive soil erosion, but agricultural terracing - another physical-threshold system - was so effective at preventing subsequent soil loss that the next spike in erosion only occurred after the landscape was abandoned and the terrace structures began failing from lack of maintenance (Fisher et al., 2003). Other 
technological innovations have made uninhabitable places habitable, resulting in ways of life that are functionally disconnected from surrounding natural systems: consider what air conditioning makes possible by masking outdoor heat and humidity, or that cities in arid basins can divert water from major river drainages over huge distances (e.g., Hundley, 2009). Technological interventions that disconnect human activities from local environmental conditions allow an anthropic "built layer... of artificial composition and structure" to be superimposed on the Earth's surface (Haff, 2003). Indeed, the frontier of innovative environmental interventions has reached the scale of geoengineering, the "intentional alteration" of natural planetary-scale processes (Caldiera et al., 2013). Mitigation technology, whether agricultural terracing, air conditioners, levees, or schemes for solar radiation management, is characteristically sensitive - strongly coupled to environmental conditions. Such responsiveness, rather like buildings designed to tolerate earthquakes, is what makes them good interventions. Technological interventions that are sensitive to environmental conditions enable humans to build and live anywhere they choose, to be effectively insensitive to environmental change, with the potential to be insulated all but entirely from natural variability.

In light of this technological track record, and assuming that strongly coupled "human dynamics" refers to societal actions rather than to physical hazard-defense infrastructure, in the near term, climate change may strengthen environmental coupling with human dynamics in systems that are already strongly coupled: settings in which mitigation actions such as river levees (Chriss and Shock, 2001; Werner and McNamara, 2007), artificial dunes (Magliocca et al., 2011), beach nourishment (Lazarus et al., 2011), and seawalls match rather than overwhelm natural system processes. Given the conditions that contribute to strong coupling between human and environmental dynamics (Werner and McNamara, 2007), it follows that coupling strength is an inherently transient property of these systems. If institutions invest in mitigation infrastructures that function as physical thresholds on the scale of Earth's global systems, climate change could ultimately reduce, rather than increase, human-environmental coupling strength observable over human timescales.

Acknowledgements. My thanks to D. E. McNamara, P. K. Haff, B. T. Werner, and M. A. Ellis for comments and conversations that contributed to the development of the ideas presented here; to the School of Earth \& Ocean Sciences and the Sustainable Places Research Institute at Cardiff University; and to G. Coco and the organizers of the Eighth Symposium on River, Coastal, and Estuarine Morphodynamics (RCEM) in Santander, Spain (June 2013).

Edited by: G. Coco

\section{References}

Abraham, R. H. and Shaw, C. H.: Dynamics, the geometry of behavior: Part 4 - bifurcation behavior, Visual Mathematics Library, Addison-Wesley, 1988.

Anderson, R. S.: Modeling the tor-dotted crests, bedrock edges, and parabolic profiles of high alpine surfaces of the Wind River Range, Wyoming, Geomorphology, 46, 35-58, 2002.

Beisner, B. E., Haydon, D. T., and Cuddington, K.: Alternative stable states in ecology, Front. Ecol. Environ., 1, 376-382, 2003.

British Geological Survey (BGS) coastal erosion summary: http://www.bgs.ac.uk/research/climatechange/environment/ coastal/caseStudies.html, last access: September 2013.

Caldeira, K. Bala, G., and Cao, L.: The science of geoengineering, Ann. Rev. Earth Pl. Sc., 41, 231-256, 2013.

Chin, A., Florsheim, J. L., Wohl, E., and Collins, B. D.: Feedbacks in human-landscape systems, Environ. Manage., 53, 2841, 2013.

Conrad, J. M.: Resource economics (2nd Edn.), Cambridge University Press, 2010.

Cooper, J. A. G. and McKenna, J.: Boom and bust: The influence of macroscale economics on the world's coasts, J. Coast. Res., 25, 533-538, 2009.

Criss, R. E. and Shock, E. L.: Flood enhancement through flood control, Geology, 29, 875-878, 2001.

Dean, R. G. and Dalrymple, R. A.: Coastal processes with engineering applications, Cambridge University Press, 2002.

Department for Environment, Food, and Rural Affairs (DEFRA): Productive Seas - Coastal Defense: http://chartingprogress.defra. gov.uk/coastal-defence, last access: September 2013.

Ells, K. and Murray, A. B.: Long-term, non-local coastline responses to local shoreline stabilization, Geophys. Res. Lett., 39, L19401, doi:10.1029/2012GL052627, 2012.

Emanuel, K: Increasing destructiveness of tropical cyclones over the past 30 years, Nature, 436, 686-688, 2005.

Fisher, C. T., Pollard, H. P., Israde-Alcántara, I., Garduño-Monroy, V. H., and Banerjee, S. K.: A reexamination of human-induced environmental change within the Lake Patzcuaro Basin, Michoacan, Mexico, P. Natl. Acad. Sci. USA, 100, 4957-4962, 2003.

Guardian (Press Association): Warning of 'significant' flood risk, available at: http://www.guardian.co.uk/uk/feedarticle/ 10330403, 11 July 2012.

Gerritsen, H.: What happened in 1953? The Big Flood in the Netherlands in retrospect, Philo. T. Roy. Soc. A, 363, 1271-1291, 2005.

Gopalakrishnan, S., Smith, M. D., Slott, J. M., and Murray, A. B.: The value of disappearing beaches: a hedonic pricing model with endogenous beach width, J. Environ. Econ. Manag., 61, 297310, 2011.

Groffman, P. M., Baron, J. S., Blett, T., Gold, A. J., Goodman, I., Gunderson, L. H., Levinson, B. M., Palmer, M. A., Paerl, H. W., Peterson, G. D., Poff, N. L., Rejeski, D. W., Reynolds, J. F., Turner, M. G., Weathers, K. C., and Wiens, J.: Ecological thresholds: the key to successful environmental management or an important concept with no practical application?, Ecosystems, 9, 1-13, 2006.

Haff, P. K.: Neogeomorphology, prediction, and the Anthropic Landscape, in: Prediction in Geomorphology, edited by: 
Wilcock, P. R. and Iverson, R. M., AGU Monograph Series, 135, 15-26, 2003.

Hartman, R.: The harvesting decision when the standing forest has value, Econ. Inq., 14, 52-58, 1976.

Higgins, A.: Lessons for the U.S. from a flood-prone land, The New York Times, A6, 14 November 2012.

Hooke, R. LeB.: On the efficacy of humans as geomorphic agents, GSA Today, 4, 217 pp., 1994.

Hooke, R. LeB.: On the history of humans as geomorphic agents, Geology, 28, 843-846, 2000.

Hundley, N.: Water and the West: the Colorado River compact and the politics of water in the American West, University of California Press, Berkeley, 2009.

Jin, D., Ashton, A. D., and Hoagland, P.: Optimal responses to shoreline changes: an integrated economic and geological model with application to curved coasts, Nat. Resour. Model., 26, 572$604,2013$.

Johnson, C. L., Tunstall, S. M., and Penning-Rowsell, E. C.: Floods as catalysts for policy change: historical lessons from England and Wales, Water Res. Devel., 21, 561-575, 2005.

Kabat, P., van Vierssen, W., Veraart, J., Vellinga, P., and Aerts, L.: Climate proofing the Netherlands, Nature, 438, 283-284, 2005.

Kabat, P., Fresco, L. O., Stive, M. J. F., Veerman, C. P., van Alphen J. S. L. J., Parmet, B. W. A. H., Hazeleger, W., and Katsman, C. A.: Dutch coasts in transition, Nat. Geosci., 2, 450-452, 2009.

Kates, R. W., Clark, W. C., Corell, R., Hall, J. M., Jaeger, C. C., Lowe, I., McCarthy, J. J., Schellnhuber, H. J., Bolin, B., Dickson, N. M., Faucheux, S., Gallopin, G. C., Grübler, A., Huntley, B., Jäger, J., Jodha, N. S., Kasperson, R. E., Mabogunje, A., Matson, P., Mooney, H., Moore, B., O'Riordan, T., and Svedin, U.: Sustainability science, Science, 292, 641-642, 2001.

Kelley, J. T. and Brothers, L. L.: Camp Ellis, Maine: a small beach community with a big problem ...its jetty, in: America's most vulnerable coastal communities, edited by: Kelley, J. T., Pilkey, O. H., and Cooper, J. A. G., Geol. S. Am. S., 460, 1-20, 2009.

Kraus, N. C.: The effects of seawalls on the beach: an extended literature review, J. Coastal Res., 4, 1-28, 1988.

Kraus, N. C. and McDougal, W. G.: The effects of seawalls on the beach: Part I, an updated literature review, J. Coastal Res., 4, 128, 1996.

Lazarus, E. D., McNamara, D. E., Smith, M. D., Gopalakrishnan, S., and Murray, A. B.: Emergent behavior in a coupled economic and coastline model for beach nourishment, Nonlin. Process. Geophys., 18, 989-999, 2011.

Leafe, R., Pethick, J., and Townend, I.: Realizing the benefits of shoreline management, Geog. J., 164, 282-290, 1998.

Limber, P. W. and Murray, A. B.: Beach and sea-cliff dynamics as a driver of long-term rocky coastline evolution and stability, Geology, 39, 1147-1150, 2011.

Liu, J., Dietz, T., Carpenter, S. R., Alberti, M., Folke, C., Moran, E., Pell, A. N., Deadman, P., Kratz, T., Lubchenco, J., Ostrom, E., Ouyang, Z., Provencher, W., Redman, C. L., Schneider, S. H., and Taylor, W. W.: Complexity of coupled human and natural systems, Science, 317, 1513-1516, 2007a.

Liu, J., Dietz, T., Carpenter, S. R., Folke, C., Alberti, M., Redman, C. L., Schneider, S. H., Ostrom, E., Pell, A. N., Lubchenco, J., Taylor, W. W., Ouyang, Z., Deadman, P., Kratz, T., and Provencher, W.: Coupled human and natural systems, AMBIO, 36, 639-649, 2007b
Lubchenco, J. and Karl, T. R.: Predicting and managing extreme weather events, Phys. Today, 65, 31-37, 2012.

Lumbroso, D. M. and Vinet, F.: A comparison of the causes, effects and aftermaths of the coastal flooding of England in 1953 and France in 2010, Nat. Hazard. Earth Sys., 2321-2333, 2011.

Magliocca, N. R., McNamara, D. E., and Murray, A. B.: Long-term, large-scale morphodynamic effects of artificial-dune construction along a barrier-island coastline, J. Coast. Res., 27, 918-930, 2011.

Marine Climate Change Impacts Programme (MCCIP): Annual Report Card 2010-2011, edited by: Baxter, J. M., Buckley P. J., and Wallace, C. J., Lowestoft, available at: www.mccip.org.uk/arc, 2010 .

Marriner, N., Morhange, C., Doumet-Serhal, C., and Carbonel, P.: Geoscience rediscovers Phoenicia's buried harbors, Geology, 34, $1-4,2006$.

McDaniel, C. N. and Gowdy, J. M.: Paradise for sale: a parable of nature, University of California Press, 2000.

McNamara, D. E., Murray, A. B., and Smith, M. D.: Coastal sustainability depends on how economic and coastline responses to climate change affect each other, Geophys. Res. Lett., 38, L07401, doi:10.1029/2011GL047207.

McNamara, D. E. and Keeler, A.: A coupled physical and economic model of the response of coastal real estate to climate risk, Nature Clim. Change, 3, 559-562, 2013.

McNamara, D. E. and Werner, B. T.: Coupled barrier islandresort model: 1. Emergent instabilities induced by strong human-landscape interactions, J. Geophys. Res., 113, F01016, doi:10.1029/2007JF000840, 2008a.

McNamara, D. E. and Werner, B. T.: Coupled barrier island-resort model: 2. Tests and predictions along Ocean City and Assateague Island National Seashore, Maryland, J. Geophys. Res., 113, F01017, doi:10.1029/2007JF000841, 2008b.

Mendelsohn, R. and Neumann, J. E. (Eds.): The impact of climate change on the United States economy, Cambridge University Press, 2004.

Mileti, D.: Disasters by design: A reassessment of natural hazards in the United States, Joseph Henry Press, 1999.

Murray, A. B., Lazarus, E., Ashton, A., Baas, A., Coco, G., Coulthard, T., Fonstad, M., Haff, P., McNamara, D., Paola, C., Pelletier, J., and Reinhardt, L.: Geomorphology, complexity, and the emerging science of the Earth's surface, Geomorphology, 103, 496-505, 2009.

Murray, A. B., Gopalakrishnan, S., McNamara, D. E., and Smith, M. D.: Progress in coupling models of human and coastal landscape change, Comput. Geosci., 53, 30-38, 2013.

National Oceanic and Atmospheric Administration (NOAA): Billion-dollar Weather/Climate Disasters, http://www.ncdc.noaa. gov/billions/events, last accessed: September 2013.

National Research Council (NRC): The drama of the commons, National Academy Press, 2002.

National Research Council (NRC): Landscapes on the edge: new horizons for research on Earth's surface, National Academy Press, 2010.

Navarro, M.: Weighing sea barriers as protection for New York, The New York Times, A21, 8 November 2012

Nicholls, R. J. and Cazenave, A.: Sea-level rise and its impact on coastal zones, Science, 328, 1517-1520, 2010. 
Nordstrom, K. F.: Beaches and dunes of developed coasts, Cambridge University Press, 2000.

Ostrom, E.: Beyond markets and states: polycentric governance of complex economic systems, Amer. Econ. Rev., 100, 1-33, 2010.

Ostrom, E., Janssen, M. A., and Anderies, J. M.: Going beyond panaceas, P. Natl. Acad. Sci. USA, 104, 15176-15178, 2007.

Phillips, L.: Sea versus senators: North Carolina sea-level rise accelerates while state legislators put the brakes on research, Nature, 486, p. 450, 2012.

Pilkey, O. H. and Wright, H. L.: Seawalls versus beaches, J. Coast. Res., 4, 41-64.

Plant, N. G., Stockdon, H. F., Sallenger Jr., A. H., Turco, M. J., East, J. W., Taylor, A. A., and Shaffer, W. A.: Forecasting hurricane impact on coastal topography, Eos Trans. AGU, 91, 65-66, 2010.

Qingzhou, W.: The Protection of China's Ancient Cities from Flood Damage, Disasters, 13, 193-227, 1989.

Rahmstorf, S. and Coumou, D. Increase of extreme events in a warming world, P. Natl. Acad. Sci. USA, 108, 17905-17909, 2011.

Scheffer, M.: Critical transitions in nature and society, Princeton University Press, 2009.

Seabrook, J.: The beach builders, The New Yorker, 42, 22 July 2013.

Slott, J. M., Murray, A. B., and Ashton, A. D.: Large-scale responses of complex-shaped coastlines to local shoreline stabilization and climate change, J. Geophys. Res. Earth Surf., 115, F03033, doi:10.1029/2009JF001486, 2010.

Slott, J. M., Smith, M. D., and Murray, A. B.: Synergies between adjacent beach-nourishing communities in a morpho-economic coupled coastline model, Coast. Manage., 36, 374-391, 2008.

Smith, K.: Environmental hazards: Assessing risk and reducing disaster (6th Edn.), Routledge, 2013.
Smith, M. D., Slott, J. M., McNamara, D. E., and Murray, A. B.: Beach nourishment as a dynamic capital accumulation problem. J. Environ. Econ. Manag., 58, 58-71, 2009.

Stern, N. N. H. (Ed.): The economics of climate change: the Stern review. Cambridge University Press, 2007.

Strudley, M. W., Murray, A. B., and Haff, P. K.: Emergence of pediments, tors, and piedmont junctions from a bedrock weatheringregolith thickness feedback, Geology, 34, 805-808, 2006.

Summers, D.: The east coast floods, David \& Charles, 1978.

Syvitski, J. P. and Kettner, A.: Sediment flux and the Anthropocene, Philos. T. Roy. Soc. A, 369, 957-975, 2011.

Thorne, C. R., Evans, E. P., and Penning-Rowsell, E. C. (Eds.): Future flooding and coastal erosion risks, Thomas Telford Services Ltd, 2007.

Tunstall, S. M. and Penning-Rowsell, E. C.: The English beach: experiences and values, Geogr. J., 164, 319-332, 1998.

Turner, B. L., Matson, P. A., McCarthy, J. J., Corell, R. W., Christensen, L., Eckley, N., Hovelsrud-Broda, G. K., Kasperson, J. X., Kasperson, R. E., Luers, A., Martello, M. L., Mathiesen, S., Naylor, R., Polsky, C., Pulsipher, A., Schiller, A., Selin, H., and Tyler, N.: Illustrating the coupled human-environment system for vulnerability analysis: three case studies, P. Natl. Acad. Sci. USA, 100, 8080-8085, 2003.

Werner, B. T. and McNamara, D. E.: Dynamics of coupled humanlandscape systems, Geomorphology, 91, 393-407, 2007.

Williams, Z. C., McNamara, D. E., Smith, M. D., Murray, A. B., and Gopalakrishnan, S.: Coupled economic-coastline modeling with suckers and free riders, J. Geophys. Res. Earth Surf., 118, 887-899, 2013.

Yokota, H. and Komure, K.: Estimation of structural deterioration process by Markov-chain and costs for rehabilitation, in: Lifecycle performance of deteriorating structures: assessment, design, and management, edited by: Frangopol, D. M., Brühwiler, E., Faber, M. H., and Adey, B., Life-cycle performance of deteriorating structures, Am. Soc. Civil Engin., 424-431, 2003. 